\title{
The analysis of the effectiveness and safety of levofloxacin in the treatment of lower respiratory tract infection
}

\author{
*Ibrahim Dughaim Alreshidi ${ }^{1}$, Khalid Mohammed Al-Mutairi² and Xie Han $^{3}$ \\ ${ }^{1}$ Department of Pharmacy, Maternity and Children Hospital, Hafar Al-Batin, Saudi Arabia \\ ${ }^{2}$ Director, Maternity and Children Hospital, Hafar Al-Batin, Saudi Arabia \\ ${ }^{3}$ Department of Clinical Pharmacy, Nanjing Drum Tower Hospital, Nanjing, P.R. China
}

\begin{abstract}
Objective of the current study was to investigate the effectiveness and safety of levofloxacin in the treatment of lower respiratory tract infection. The study was carried out in hospital on 120 patients with lower respiratory tract infection from January 2014 to January 2015. Patients were randomly divided into control and observation groups, each group contained 60 patients. The control group was given the routine dose of levofloxacin, whereas the observation group received the high dose of levofloxacin. The clinical effectiveness and incidence rate of untoward reactions between the two groups were statistically analyzed and evaluated. Patients cure rate in the observation group was $53.33 \%$, significantly higher than that of the control group which was only $36.67 \%$. Their differences have statistical significance $(\mathrm{P}<0.05)$. Observation group demonstrated a very good total effective rate of $93.33 \%$, compared to the control group $(78.33 \%)$. Their differences have statistical significance $(\mathrm{P}<0.05)$. Incidence of adverse reactions in case of both the observation and control group patients, were relatively low, resulting insignificant statistical difference between the groups $(\mathrm{P}>0.05)$. This study shows better clinical curative effect of high doses of levofloxacin treating lower respiratory infection with minimum risk. This method, which can significantly improve the quality of patient treatment with low adverse reaction risk, is worth popularizing in clinical use.
\end{abstract}

Key Words: lower respiratory tract infection, levofloxacin, effectiveness, safety analysis.

\section{INTRODUCTION}

Lower respiratory tract infections (LRTI), is a common respiratory disease in both pediatric and geriatric patients. The incidence of LRTI tends to rise year by year and the mortality rate is significantly high, especially for aged people, because of their low body immunity due to coexistence of other diseases (Cios et al., 2014; Affara and Shaarawy, 2015; Piotrowicz et al., 2015). With the inappropriate application of clinical antibiotics and the increased drug-resistant strain, treatments of pulmonary infections are getting tough. Many of the antibiotics molecules are now-a-days almost obsolete and newer antibiotics are in practice, such as quinolone antibiotics (Cheng et al., 2013; Heppner et al., 2013; Wang et al., 2014). Several researchers suggested that quinolones are concentration dependent drugs, having a superior tissue penetration and great bioavailability in the body (Zhao et al., 2014a; Hooper and Strahilevitz, 2015).

Levofloxacin is the third generation of fluoroquinolones with wide antibacterial spectrum, low side effects and greater tissue penetration. The routine dose is $200 \mathrm{mg}$ each time with two doses per day (Stein et al., 2008; Unnikrishnan et al., 2015). Pharmacokinetic (PK) and pharmacodynamic (PD) studies of many antibacterial drugs (including quinolone) are deepening continuously. Recent studies suggested that it is more rational and beneficial to use high-dose $(55 \mathrm{mg} / 750 \mathrm{mg})$ levofloxacin. The drug was well-tolerated with very little or no rise in the occurrences of drug adverse reactions (Wimer et al., 1998; Zhao et al., 2014b). However, many health practi-

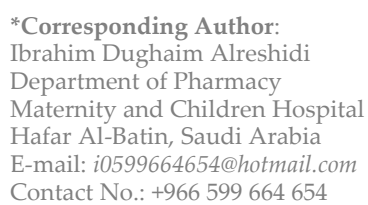

tioners are still worried about the safety of using highdose levofloxacin. So, these clinical trials have been designed to compare the quality of treatment between low- and high-dose applications of levofloxacin to treat lower respiratory infection.

\section{MATERIALS AND METHODS}

\section{General materials}

This study was conducted over 12 months period in Nanjing Drum Tower Hospital, Nanjing, P.R. China in between January, 2014 and January, 2015. A total of 120 patients with existing lower respiratory tract infection were selected and randomly divided into control group and observation group. Control group consisted of 34 males and 26 females with an average age of $58.1 \pm 4.3$ years. There were 38 cases with pneumonia (CAP), 6 cases with bronchiectasia and 16 cases with acutely paroxysmal of chornically asthmatic bronchitis. There were 32 males and 28 females in observation group and the average age was $58.1 \pm 4.9$ years. There were 22 cases with pneumonia (CAP), 7 cases with bronchiectasia and 16 cases with acutely paroxysmal of chornically asthmatic bronchitis. The age, sexuality and conditions has no significant differences $(\mathrm{p}>0.05)$.
Treatment
Patients of the two groups were treated conventional therapy with removing phlegm, preventing asthma and relaxing cough but the patients of observation group were treated with levofloxacin (The First Pharmaceutical Limited Company of Japan in Beijing, H2009103456) with the specification of $0.5 \mathrm{~g} / 100 \mathrm{ml}$ by intravenous drip. Patients of control group were treated with levofloxacin lactate injection (Chongqing Kerui Pharmaceutical Limited Company, Lot Number 050105) with the specifi- cation of $200 \mathrm{mg} / 100 \mathrm{ml}$ by intravenous drip. The administration time for both groups were less than 10 
Table 1: Comparison of treatment effectiveness between the two groups [n (\%)].

\begin{tabular}{|c|c|c|c|c|c|c|}
\hline Group & Cases & Cure rate & $\begin{array}{c}\text { Obviously curative } \\
\text { rate }\end{array}$ & $\begin{array}{l}\text { Effective } \\
\text { rate }\end{array}$ & $\begin{array}{l}\text { Ineffective } \\
\text { rate }\end{array}$ & $\begin{array}{l}\text { Total effective } \\
\text { rate }\end{array}$ \\
\hline Observation group & 60 & $32(53.33 \%)$ & $12(20.00 \%)$ & $12(20.00 \%)$ & $4(6.67 \%)$ & $93.33 \%$ \\
\hline Control group & 60 & $22(36.67 \%)$ & $16(26.66 \%)$ & $9(15.00 \%)$ & $13(21.67 \%)$ & $78.33 \%$ \\
\hline P-value & - & $<0.05$ & $>0.05$ & $>0.05$ & $<0.05$ & $<0.05$ \\
\hline
\end{tabular}

days and treatment was ceased once clinical pulmonary infection score (CPIS) reached below 6. To evaluate the clinical effectiveness of the ongoing treatment, routine blood, urine, serum electrolyte and blood sugar examinations were carried out for both groups. Chest X-ray examination or chest $\mathrm{CT}$ examination were also employed as appropriate.

\section{Assessment standard of effectiveness}

According to the assessment standard of Clinical Application of Antimicrobial Drugs Guiding Principles (Xia, 2004), here are the definitions- Cure: After the treatment, the patients' clinical symptoms disappeared completely; Excellence: There are five aspects including symptom, sign, hemogram, chest images and sputum-bacterial examination, and 3 or above 3 of them had returned to normality or marked improvement; Effective: After the treatment, patients' clinical symptoms had alleviated to a certain degree; Ineffective: Patients' conditions did not get better or even worse and clinical symptom did not get any changes.

The total effective rate $=($ the cure rate + obvious curative rate + the effective rate).

\section{Outcome measures}

During and after the treatment, treatment effect and incidence rate of adverse effect of the two groups were observed and analyzed statistically.

\section{Statistical method}

All the data were analyzed with the SPSS® 18.0 software, and using t-inspection and $\mathrm{x} 2$ inspection. Numbers were considered as statistically significantly different when $p$ value was found lower than $0.05(\mathrm{p}<0.05)$.

\section{RESULTS}

Comparing treatment effectiveness

The cure rate and the total rate of observation group are all obviously higher than control group $(\mathrm{P}<0.05)$. Full details are in table 1.

\section{Comparing incidence rate of adverse effect}

There was no significant differences between the two groups ( $\mathrm{p}>0.05)$. Full details are in table 2.

\section{DISCUSSION}

Lower respiratory infection includes acutely paroxysmal of chronically asthmatic bronchitis, CAP, bronchiectasia and pneumonia. Types of responsible pathogens are complicated and in most of the case is mainly Gram negative bacterium. Incidences of complex infection have gradually increased day by day because of antibiotics abuse (Hur et al., 2012; Chidambaram, 2014; Currie et al., 2014). So, to overcome these difficulties, we have to treat them from all kinds of aspects by analyzing. We generally use MIC to measure the antibacterial activity of antibiotics and this is the dates which are from extracorporal measures that are reflected in the concentration. When clinicians make choice among different types of antibiotics and medication plans, they should not only just think
Table 2: Comparison of incidence rate of adverse effect between the two groups [n (\%)].

\begin{tabular}{cccccc}
\hline Group & Cases Dizziness & Erythra & Agrypnia & Phlebitis \\
\hline $\begin{array}{c}\text { Observation } \\
\text { group }\end{array}$ & 60 & $1(1.67 \%)$ & $0(0.00 \%)$ & $1(1.67 \%)$ & $1(1.67 \%)$ \\
$\begin{array}{c}\text { Control } \\
\text { group }\end{array}$ & 60 & $2(3.33 \%)$ & $1(1.67 \%)$ & $0(0.00 \%)$ & $1(1.67 \%)$ \\
\begin{tabular}{c} 
P-value \\
\hline
\end{tabular} & - & $>0.05$ & $>0.05$ & $>0.05$ & $>0.05$ \\
\hline
\end{tabular}

about the temporary effects, but also about avoiding drug-resistant strain production. Recent researches regarding the new quinolone molecules mentioned a concept of mutant prevention concentration (MPC). It refers to the antibiotic concentration at the selective drugresistant strain cannot grow and we call it mutant selection window. When antibiotics are used in clinical treatment, we should narrow mutant selection window by selecting the new drugs, adjusting the dose and combining the drugs.

Levofloxacin, laevo isomer of ofloxacin (Wimer et al., 1998), shows its pharmacological activities by stopping bacterium's DNA from synthetizing and reproducing which eventually causes bacterium's death by controlling the activity of gyrase and topoisomerase in bacterium's DNA. Like many other antimicrobial drugs, levofloxacin's antimicrobial activity is concentration dependent. The higher the concentration is, the stronger its bactericidal activity is. The main PK/PD parameter is the ratio of blood peak concentration and MIC. The size of the ratio closely depends on drug efficacy and bacterial removal. Some clinical research data suggested a large dose of levofloxacin can slow the production of drugs and efficiently clean up pathogens in a short time. Because the exposed time of bacteria is shorter, the speed of sterilization is faster. Also, reducing the amount of bacteria or reducing the amount of allergic lower subgroup bacteria to the lowest can directly prevent emerging drug resistance. From table 2, we can see using a large dose of levofloxacin did not increase the rate of adverse effect.

\section{CONCLUSION}

In can be concluded that a large dose of levofloxacin in lower respiratory tract infection treatment is convenient, economic and can raise patients' compliance. At the same time, it has high clinical value and safety which can also improve patients' clinical effectiveness.

\section{REFERENCES}

Affara, N., Shaarawy, H., (2015). Study of the pattern of lower respiratory tract infection within the first year in renal transplant patients. Egyptian Journal of Chest Diseases and Tuberculosis, 64(3), 749-753. [DOI]

Cheng, G., Hao, H., Dai, M., Liu, Z., Yuan, Z., (2013). Antibacterial action of quinolones: From target to network. European Journal of Medicinal Chemistry, 66, 555-562. [DOI]

Chidambaram, R., (2014). Final thoughts on antibiotic use: Wake up call for the oral health care professionals. Asian Pacific Journal of Tropical Biomedicine, 4, Supplement 2, S554-S559. [DOI]

Cios, A., Wyska, E., Szymura-Oleksiak, J., Grodzicki, T., (2014). Population pharmacokinetic analysis of ciprofloxacin in the elderly patients with 
lower respiratory tract infections. Experimental Gerontology, 57, 107113. [DOI]

Currie, J., Lin, W., Meng, J., (2014). Addressing antibiotic abuse in china: An experimental audit study. Journal of Development Economics, 110, 39-51. [DOI]

Heppner, H.J., Cornel, S., Peter, W., Philipp, B., Katrin, S., (2013). Infections in the elderly. Critical Care Clinics, 29(3), 757-774. [DOI]

Hooper, D.C., Strahilevitz, J., (2015). 34 - quinolones. In: Blaser, J.E.B.D.J. ed. Mandell, douglas, and bennett's principles and practice of infectious diseases (eighth edition), Philadelphia, pp. 419-439.e418.

Hur, J., Jawale, C., Lee, J.H., (2012). Antimicrobial resistance of salmonella isolated from food animals: A review. Food Research International 45(2), 819-830. [DOI]

Piotrowicz, K., Klich-Rączka, A., Pac, A., Zdzienicka, A., Grodzicki, T. (2015). The diurnal profile of melatonin during delirium in elderly patients-preliminary results. Experimental Gerontology, 72, 45-49. [DOI]

Stein, G.E., Schooley, S.L., Nicolau, D.P., (2008). Urinary bactericidal activity of single doses $(250,500,750$ and $1000 \mathrm{mg})$ of levofloxacin against fluoroquinolone-resistant strains of escherichia coli. International Journal of Antimicrobial Agents, 32(4), 320-325. [DOI]
Unnikrishnan, R, El-Shafei, A, Klein, E. A, Jones, J.S, Kartha, G, Goldman, H.B., (2015). For single dosing, levofloxacin is superior to ciprofloxacin when combined with an aminoglycoside in preventing severe infections after prostate biopsy. Urology, 85(6), 1241-1246. [DOI]

Wang, Y.-T., Lee, M.-F., Peng, C.-F., (2014). Mutations in the quinolone resistance-determining regions associated with ciprofloxacin resistance in pseudomonas aeruginosa isolates from southern taiwan. Biomarkers and Genomic Medicine, 6(2), 79-83. [DOI]

Wimer, S.M., Schoonover, L., Garrison, M.W., (1998). Levofloxacin: A therapeutic review. Clinical Therapeutics, 20(6), 1049-1070. [DOI]

Xia, G., (2004). The guiding principles of clinical application of antimicrobial drugs, Chinese Medicine Press, Beijing.

Zhao, X., Malik, M., Hong, Y., Li, L., Drlica, K., (2014a). Quinolones 2 . Reference module in biomedical sciences. Elsevier.

Zhao, X., Wu, J.-F., Xiu, Q.-Y., Wang, C., Zhang, D.-P., Huang, J.-A., Xie, C.-M., Sun, S.-H., Lv, X.-J., Si, B., Xiao, Z.-K., Zhang, Y.-Y., (2014b). A randomized controlled clinical trial of levofloxacin $750 \mathrm{mg}$ versus 500 $\mathrm{mg}$ intravenous infusion in the treatment of community-acquired pneumonia. Diagnostic Microbiology and Infectious Disease, 80(2), 141 147. [DOI] 